\title{
The interaction of northern wind flow with the complex topography of Crete Island - Part 2: Numerical study
}

\author{
I. Koletsis ${ }^{1,2}$, K. Lagouvardos ${ }^{1}$, V. Kotroni ${ }^{1}$, and A. Bartzokas ${ }^{2}$ \\ ${ }^{1}$ National Observatory of Athens, Institute of Environmental Research, 15236 Palaia Penteli, Athens, Greece \\ ${ }^{2}$ University of Ioannina, Department of Physics, Laboratory of Meteorology, 45110 Ioannina, Greece
}

Received: 3 February 2010 - Revised: 7 May 2010 - Accepted: 10 May 2010 - Published: 7 June 2010

\begin{abstract}
During the summer months, when northerly winds are blowing over the Aegean Sea the island of Crete modifies significantly the regional airflow as well as the pressure and temperature fields due to its complex topography. One of the major topographical elements of Crete Island is the major gap which is located between the two highest mountains Lefka Ori and Idi. On 24-25 August 2007 strong northerly winds, with gusts up to $25 \mathrm{~m} \mathrm{~s}^{-1}$, occurred at the exit of the major gap. In order to investigate the dynamics as well as the role of this elevated and sloping gap on the airflow modification, the event was simulated down to $1 \mathrm{~km}$ horizontal resolution using the non-hydrostatic model MM5. The model simulations show that the localized intensification of the flow downstream of the major gap is related to the channeling of the flow through the gap. The strongest winds are observed at the gap exit region, implying that the main cause of the strong winds is the pressure different between the gap entrance and exit, when the relatively cooler maritime air approached the island and dammed up the high mountains. Finally, sensitivity experiments with modified topography further supported the important role of the topography of the elevated gap, which reveals that the strong winds have aspects of both gap and downslope contributions over the gap exit.
\end{abstract}

\section{Introduction}

One of the major meteorological characteristics that occur over the Aegean Sea during summer months is the onset of strong winds from northern directions, named Etesians. The

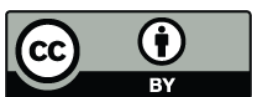

Correspondence to: I. Koletsis

(koletsis@meteo.noa.gr)
Etesians constitute a major climatic element because they moderate the summer heat, as they are cool over the Aegean. They affect tourism and sailing and they clean the heavily polluted Athens atmosphere. Climatically speaking, the Etesians could be characterized as monsoonal type winds, in spite their large diurnal variation, prevailing over a large area of the east Mediterranean. However, for each individual day in the Aegean Sea they can be considered as a synoptic phenomenon. The necessary pressure gradient appears to have been caused by the extension up to western Turkey of the summer permanent thermal low pressure trough of the Anatolian plateau and by a high pressure ridge over the Balkans, which is either strong or weak according to upper air synoptic conditions (Metaxas, 1973; Metaxas and Bartzokas, 1994; Ziv et al., 2004).

The Aegean Sea consists of numerous islands which modify significantly the general wind flow. The most important modification takes place around the Crete Island, which is the largest island in the Aegean. Crete Island is located in the southern Aegean Sea, southeast of the greek continental mainland. The island has a long and narrow shape, with its west-east axis oriented perpendicular to the summer prevailing northern wind flow. The central and the western part of the island are characterized by high mountains with peaks reaching $2400 \mathrm{~m}$, while mountains with lower crests are found on the eastern part (Fig. 1a).

In the island, numerous gaps are found between the mountains. One of the more important gaps is situated between the two highest mountains, Lefka Ori (2453 m) and Idi (2456 m). Topography of this gap plays a decisive role in the formation of the local strong winds. It has a north-south length of $23 \mathrm{~km}$, and a width of $\sim 30-40 \mathrm{~km}$. The gap does not have a simple, smoothed terrain; many hills and smaller mountains that range from 100 to $600 \mathrm{~m}$ in elevation give to the gap topography an elevated sloping character, especially near

Published by Copernicus Publications on behalf of the European Geosciences Union. 


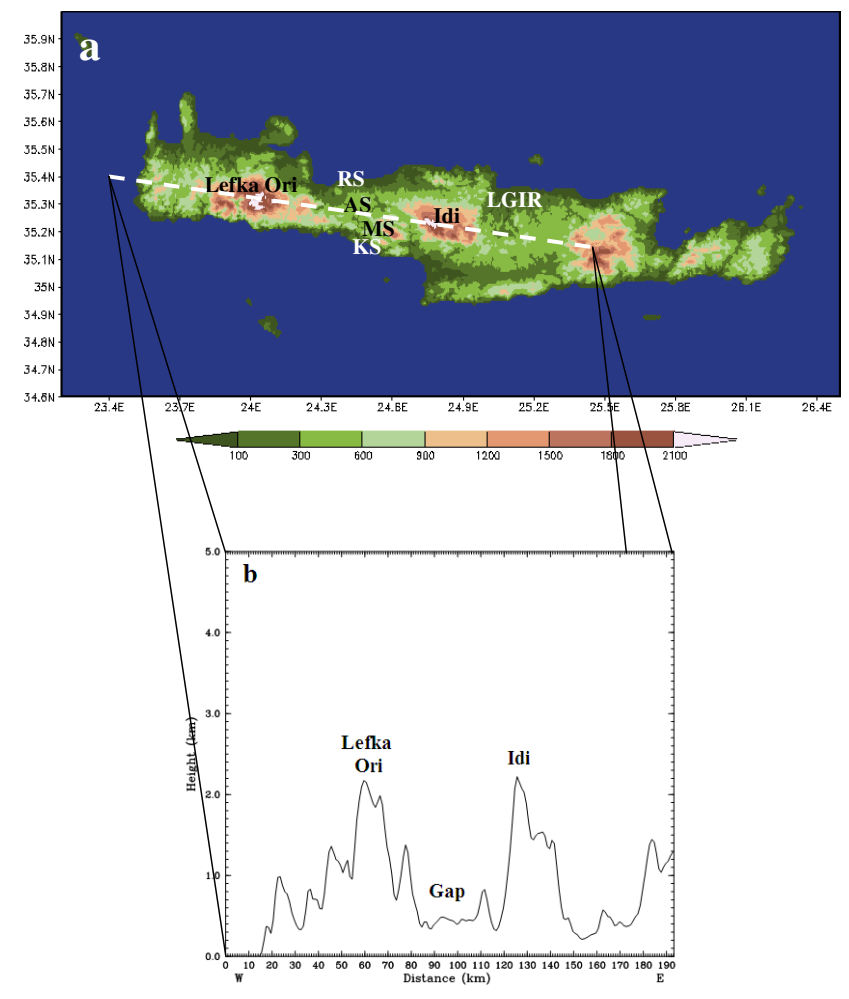

Fig. 1. (a) Topographic map of Crete Island and geographical locations of the ground stations at Rethymno (RS), Armeni (AS), Mourne (MS) and Kerame (KS) as well as the location of Heraclion Airport (LGIR). The mountains Lefka Ori and Idi, referred to in the text, are also shown. (b) The island profile as seen from the south. The mountains as well as the gap location are marked. The profile was created from MM5 grid 3 topographic dataset (at $1 \mathrm{~km}$ grid increment).

the southern coasts. The topography profile of Crete Island (Fig. 1b) shows the location of the major gap as well as the main topographic features of the island. The position of this gap among the highest mountains, and the orientation of the island to the prevailing northern wind regime during summer provide an excellent example in order to study the interaction of gap geometry with the northerly winds.

This paper is the second in a series examining the interaction of the northern wind flow over the Aegean Sea with the complex topography of Crete Island, and particular the significance of the major gap flow. In Part 1 of this series, (Koletsis et al., 2009, denoted as K09 in the remainder of the paper), an extensive observational analysis using 92-days of data (July-September 2007) from four meteorological stations deployed along the gap (as shown in Fig. 1a), high-resolution satellite wind data from QuikSCAT (wind retrievals with a horizontal spatial resolution of $12.5 \mathrm{~km}$ ) and soundings data, was performed. According to the satellite sensor specifications, the QuikSCAT winds have an accuracy of $\pm 0.2 \mathrm{~m} \mathrm{~s}^{-1}$ for the wind speed and $\pm 20^{\circ}$ for the direction. Some of K09's principal findings are referred below:
- The stronger winds were observed at and near the gap exit and decreased gradually to the north (Fig. 1a). The prevailing wind direction was the northern and the small differences observed among the stations were related with the local topographical elements.

- In gap entrance (RS station) a significant percentage of south winds were observed during the nighttime revealing the presence of a land breeze.

- The stronger winds were observed at gap exit (KS) contrary to the Venturi effect, indicating that the main cause is the pressure difference between the gap entrance (RS) and exit (KS).

- Throughout the days of northerly prevailing flow, an increase in mean maximum temperatures as well as a decrease of relative humidity were observed at the southern edge of the gap (KS station) resulting from the adiabatic warming from the adjacent mountains and gap topographical elements.

Finally, the case of 24-25 August 2007 when strong wind gusts reached $25 \mathrm{~m} \mathrm{~s}^{-1}$, was further analysed in K09. During this event a large number of forest fires were reported in the southern parts of continental Greece and in the islands of the Aegean Sea (Evoia and Crete), that have caused extensive destruction and up to 63 deaths. The major conclusions of this case include the following:

- The QuikSCAT data revealed the formation of a deceleration zone of about $110 \mathrm{~km}$ upstream of the island and a deflection of the wind flow around the island. Moreover, formations of mountain wakes (airflow disruptions) as well as narrow stripes of increased wind speed were observed downstream of the island.

- The sounding at Heraclion Airport (LGIR in Fig. 1a) reavealed two stable layers in the lower troposhere. More specifically a marine temperature inversion was located below the summit of the mountain Idi resembling the formation of anticyclonic föhn according to Cadez's classification (1967).

- The stronger winds were observed at the gap exit (KS) while the changes of pressure difference between gap entrance and exit with the wind intensity in KS were in phase.

A number of studies in the literature have documented the structure and dynamics of gap flows using numerical models in other areas of the world. Smith et al. (1997) used two numerical models in order to simulate St. Vincent's wakes in southeastern Caribbean. Both models indicated that air descent, acceleration, wave breaking and weak potential vorticity generation occurred over the island affecting the form of the wakes. Steenburgh et al. (1998) used MM5 model to examine the structure and the dynamics of a gap flow event 
over Gulf of Tehuantepec, Mexico. Model-derived momentum balances as well as trajectories analyses were used to examine the dynamics of flow curvature over the Gulf of Tehuantepec and its correlation with the cross-flow pressure gradient. Moreover, Colle and Mass (2000) using also MM5 model simulations down to $1.33 \mathrm{~km}$ grid increment, studied the easterly gap flow through the Strait of Juan de Fuca, in the international boundary area between the USA. and Canada. Sensitivity test with modified coastal topography was also performed. The authors have shown the significant role of the surrounding topography as well as of the cross-strait pressure gradient to the gap outflow. In Europe many studies have been devoted to the gap flow during a bora episode. Mayr et al. (2007) presents the results from the Mesoscale Alpine Programme (MAP) regarding the gap flows, in which three gap flow prototypes were found and examined. Also, Gohm et al. (2008) investigates a strong Adriatic bora windstorm near a mountain gap using observational and numerical data. The windstorm was characterized by a highly transient and a three-dimensional wind field downstream of the mountain gap.

Modeling studies focusing on the study of the interaction of the wind flow with the complex topographic features of the Aegean Sea are limited. Kotroni et al. (2001) using the hydrostatic model BOLAM provided some further insight on the orographically disturbed wind flow. These authors have shown that the interaction of the northerly wind flow with the Cretan mountains produces deceleration of the flow up to $120 \mathrm{~km}$ upstream, a leftward deflection of the air and an intensification of the flow east of the island. Although the model results showed a good agreement with the observations, they did not capture the localized maximum wind speeds at the maritime area downstream of the main gap.

Since such strong wind events are quite frequent over the maritime area at the gap exit of Crete Island, which is an important waterway for commercial and recreational use and a cause of rapid spread of forest fires at adjacent mountainous areas inside the gap, it is important to improve the understanding of the three dimensional structure and the mechanisms associated with this gap flow. This paper examines the strong wind event of 24-25 August 2007 using high-resolution simulations performed with the MM5 nonhydrostatic model. One of the main goals is to determine whether the model can successfully simulate the modification of the flow across this elevated gap. Furthermore, the essential dynamics of the presence of the gap is examined by performing simulations with modified topography.

The arrangement of this paper is as follows: Sect. 2 presents the main features of the numerical model used in this study, together with the information about the settings of the various simulations that have been performed. The results of the control run simulations are presented at Sect. 3, while the results of the sensitivity tests are discussed in Sect. 4. The final section is devoted to the concluding remarks of this work.

\section{Model and set-up}

The non-hydrostatic model MM5 was used to simulate this case and to provide additional data for diagnosing the gap flow. MM5 is a non-hydrostatic, primitive equation model using terrain-following coordinates (Dudhia, 1993). Several physical parameterization schemes are available in the model for the boundary layer, the radiative transfer, the microphysics and the cumulus convection. The MM5 model has been running operationally at the National Observatory of Athens since 2000 and at the University of Ioannina since 2007. For both the operational use and also for this case study, the following schemes are selected: the KainFritsch scheme (Kain and Fritsch, 1993) for the convective parameterization, the explicit microphysics scheme proposed by Schultz (1995) and the scheme proposed by Hong and Pan (1996) for the planetary boundary layer (named MRF scheme). The selection of the combination of the KainFritsch scheme for convection and the Schultz scheme for explicit microphysics is based on the comparative study by Kotroni and Lagouvardos (2001). Also, the selection of the planetary boundary layer scheme is based on the finding by Akylas et al. (2007) who verified the operational forecasts with MM5 model over Athens with three schemes for the warm period 2002 and found that the MRF scheme produces the most consistent forecasts.

For the simulations, the ECMWF gridded analysis fields (6-h interval), at 0.5-degree lat/lon horizontal grid increment have been used as initial and boundary conditions. Three one-way nested grids are defined and used: (a) Grid 1, with $220 \times 140$ grid points at an horizontal increment of $16 \mathrm{~km}$, covering the major part of Europe, the Mediterranean and the northern African coast, (b) Grid 2, with $185 \times 205$ grid points at an increment of $4 \mathrm{~km}$, covering the major Greek area including the islands of the Aegean Sea, and (c) Grid 3, with $249 \times 205$ grid points at a grid increment of $1 \mathrm{~km}$, covering the western region of the South Aegean Sea and the mountainous central and western part of the Crete Island. The horizontal extension of all three grids is shown in Fig. 2. Many recent studies, found in literature, deal with the use of very-high resolution modeling. Doyle (1997), Colle and Mass (2000), and Kotroni and Lagouvardos (2004) among others, have shown that increasing horizontal resolution could be very advantageous, especially in cases of circulations forced by topography and surface contrasts. In the vertical thirty-nine unevenly spaced full-sigma levels were used, with the maximum resolution in the boundary layer. The model top was set at $100 \mathrm{hPa}$. A 48 -h simulation initialized at 00:00 UTC 24 August 2007 was completed for all model domains.

Moreover, in addition to the control run (CNTL, hereafter), a sensitivity simulation was performed with modified topography of Grid 3, while all the rest of the setup characteristics were exactly the same to the CNTL simulation. In the 


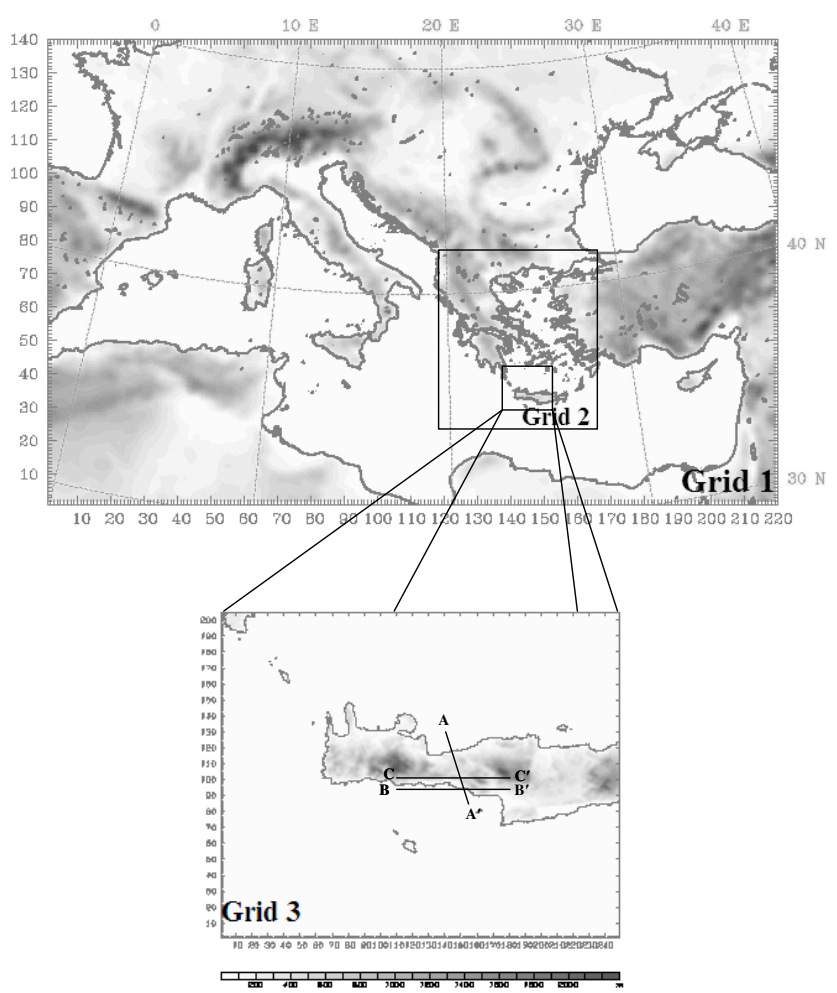

Fig. 2. Horizontal extensions of MM5 grids. The rectangles inside the Grid 1 area (16 km grid spacing) denote the location of Grid 2 (4 km grid spacing) and Grid 3 (1 km grid spacing). Model terrain shaded every $100 \mathrm{~m}$ for all domains. Lines $\mathrm{AA}^{\prime}, \mathrm{BB}^{\prime}$ and $\mathrm{CC}^{\prime}$ denote the positions of the cross sections shown in Figs. 6, 7, and 8.

sensitivity test (FULLGAP hereafter), the terrain inside the gap was diminished so as the gap elevation would be at a lower constant height of $\sim 100 \mathrm{~m}$.

\section{Model results - CNTL simulations}

\subsection{Synoptic analyses}

During the days of 24-25 August 2007 strong northerly winds were observed over the Aegean Sea, when an Etesian wind regime was established (further observational details of this case are given in K09). Near gale winds were observed at the southern coasts of Crete Island and especially through the major gap in which wind gusts at the exit (KS) reached $25 \mathrm{~m} \mathrm{~s}^{-1}$. Figure 3 presents the $500 \mathrm{hPa}$ height level and the mean sea level pressure at 06:00 UTC 24 August 2007 during the time of the maximum observed winds at the gap exit, as simulated by MM5 grid 1 at $16-\mathrm{km}$ resolution.

A $500 \mathrm{hPa}$ trough was located over eastern Turkey while a narrow eastward tilted upper-level ridge was present over the Ionian Sea and the Balkans. At surface, a depression was situated over southern Turkey and Cyprus with a low center of $\sim 1006 \mathrm{hPa}$. This low pressure system is called the Turkish thermal low and is considered as a western extension of the

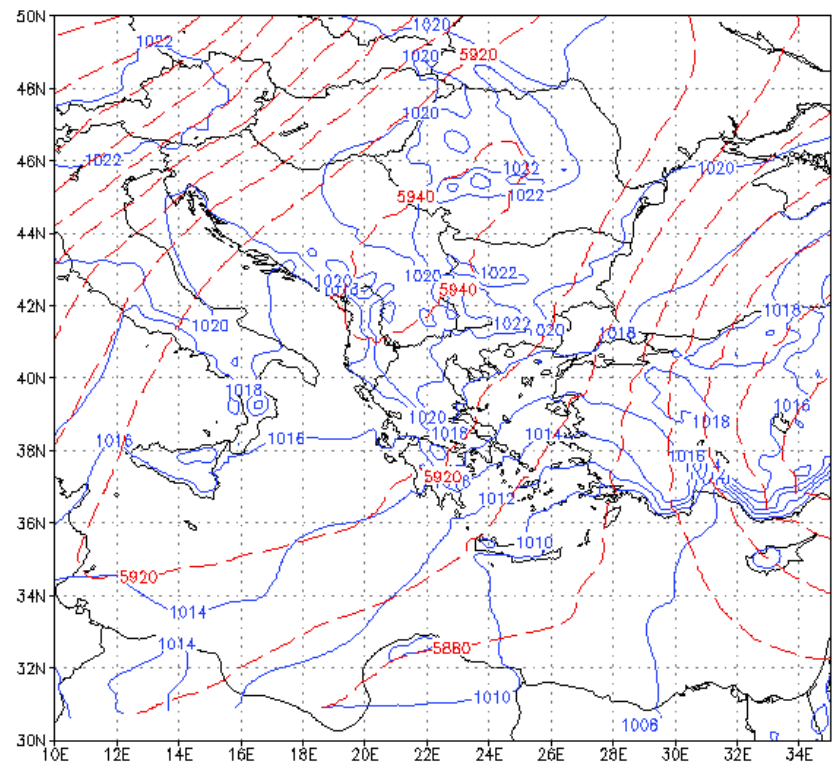

Fig. 3. MM5 coarse grid mean sea level pressure (at $2 \mathrm{hPa}$ intervals, solid blue lines) and $500 \mathrm{hPa}$ geopotential height (at $20 \mathrm{~m}$ intervals, dashed red lines) valid at 06:00 UTC 24 August 2007 (6h forecast), zoomed over the area of Balkans from the CNTL simulation.

Asian thermal low (Meteorological Office, 1962). A pressure gradient of $\sim 5 \mathrm{hPa}$, over a distance of $300 \mathrm{~km}$ from the western-southwestern Turkish coasts to the eastern continental Greece was evident over the Aegean Sea resulted in the strong northern flow. Comparison of the model simulation with the ECMWF analyses (Fig. 7 in K09) reveals that the synoptic field as well as the pressure gradient over the study area was simulated adequately by the model.

\subsection{Horizontal analyses}

In order to study the wind flow around the island the simulated horizontal field from Grid 3 (at $1 \mathrm{~km}$ grid spacing) will be discussed. Figure 4a shows the 10-m wind at 06:00 UTC 24 August 2007. Upstream of the island the simulated general airflow reveals a deceleration zone with a horizontal extent of about $90 \mathrm{~km}$ over the maritime area north of Crete. Within this zone the wind speeds decrease from $12.5 \mathrm{~m} \mathrm{~s}^{-1}$ to $2.5 \mathrm{~m} \mathrm{~s}^{-1}$ just offshore of RS. In addition, a noticeable gradual leftward turn of the wind (facing downstream) is evident. The strongest winds are reproduced by the model over the area which is located upstream of western Crete, where both observations (Fig. 8 in K09) and simulated winds are of the order of $10-12.5 \mathrm{~m} \mathrm{~s}^{-1}$.

On the central and western leeward side of the island the weak flow from variable directions $\left(<5 \mathrm{~m} \mathrm{~s}^{-1}\right)$ suggests the presence of two mountain wakes downwind of the higher peaks of the Cretan mountains. The wakes of the island consists of small-scale counter-rotating vortices. In order to investigate the vertical extent of the low-level vortices, the 

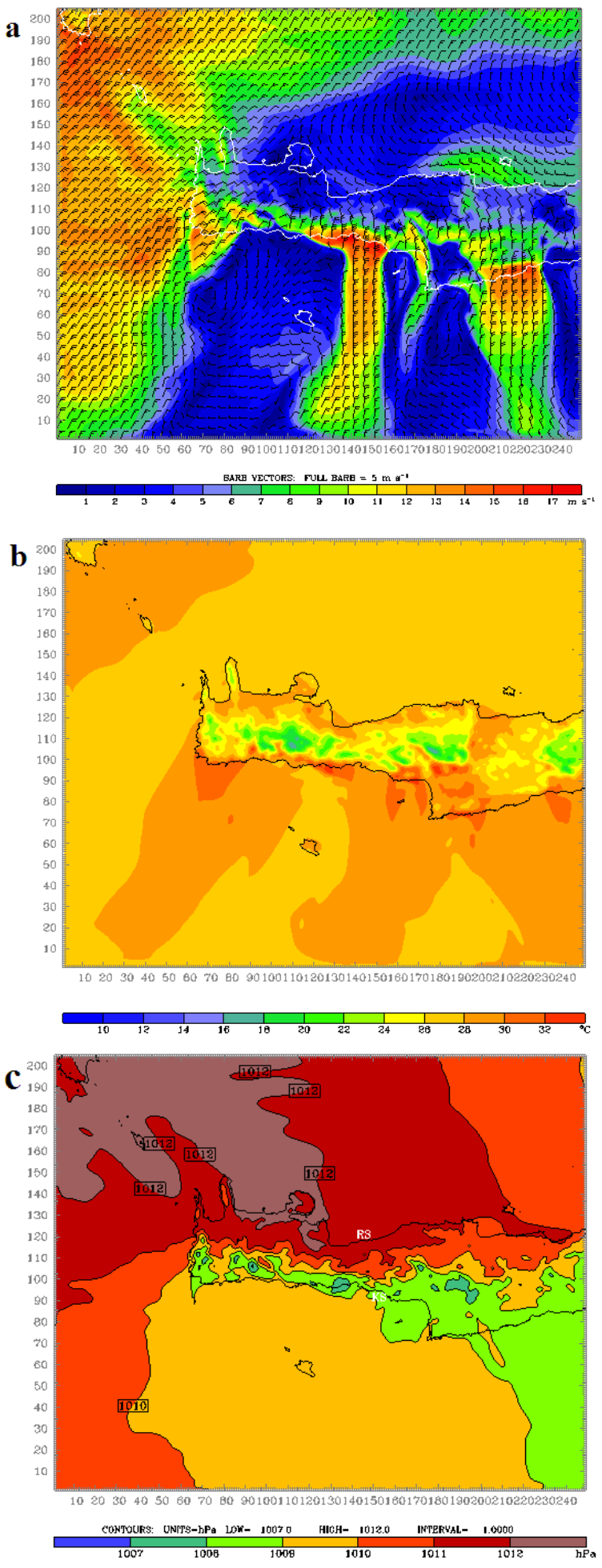

Fig. 4. (a) Plan view of $10 \mathrm{~m}$ wind and (b) temperature field from MM5 Grid 3, valid at 06:00 UTC 24 August 2007 (6h forecast), from the CNTL simulation. A full barb corresponds to $5 \mathrm{~m} \mathrm{~s}^{-1}$. Colored shading shows the wind intensity. Wind symbols are plotted every 5 grid points. (c) Plan view of mean sea level pressure from MM5 Grid 3, valid at 06:00 UTC 24 August 2007 (6h forecast), from the CNTL simulation. The location of RS and KS are also indicated. wind fields at lower tropospheric layers were studied (not shown). The results revealed that the wakes were shallow as their vertical extent was restricted below the level of $2000 \mathrm{~m}$. Furthermore, the horizontal extent of the vortices was diminished significantly above $1000 \mathrm{~m}$ (not shown). On the other hand, restricted areas with strong winds are evident offshore and are associated with gap flows. More specifically, offshore of the major gap the wind speed exceeds $10 \mathrm{~m} \mathrm{~s}^{-1}$ and extends in a region up to $40-50 \mathrm{~km}$ with a gradually deceleration as the flow moves farther downstream.

A significant number of studies have been devoted to the downstream extension of gap outflow. Gap outflow winds can extend several hundred kilometers downstream (e.g. Gulf of Tehuantepec, Steenburgh et al., 1998; Gulfs of Panama and Papagayo, Legeckis, 1988) or is restricted in a zone of few tens of kilometers weakening or merging with the ambient flow (e.g. in the Strait of Juan de Fuca, Overland and Walter, 1981; in Wide Bay, Alaska, Bond and Macklin, 1993). Just offshore KS, as the northerly flow moves out the gap, it seems to accelerate because of reduced surface drag over water (Mass et al., 1995; Hsu, 1988). Moreover, along the downstream east-west axis, in the edges of the gap outflow, a strong horizontal shear is evident. In general, the model reproduces very well the observed deceleration of the wind flow upstream of the island, the leftward deflection, and also the wake south of Crete, features also evident in the QuikSCAT wind field (Fig. 8 in K09) during the time of the maximum winds over the gap exit area.

The 2-m temperature field around the island during the time of the maximum gap winds is illustrated in Fig. 4b. The highest simulated temperatures are located just downwind of the highest mountains as result of the descending warmer air, while relative lower temperatures are observed offshore the gap exit indicating that the major gap seems to provide a "conduit" for maritime air across the island. Also, the sea level pressure field reveals a pressure difference between the windward and the leeward coasts of the island (Fig. 4c). At 06:00 UTC 24 August 2007 the pressure is $4 \mathrm{hPa}$ higher at the upwind than at the downwind location which is a common characteristic in areas of airflow blocked by high mountains (Smith, 1982; Kotroni et al., 2001), while the pressure difference between the entrance and the exit of the gap is $\sim 3 \mathrm{hPa}$ (Fig. 4c).

\subsection{Time series - Froude and Rossby number}

One of the major questions to be addressed here is whether the model can successfully simulate the observed wind field throughout the gap. For this reason time series comparison between the simulated and observed wind speed for all ground gap stations are presented in Fig. 5a-d. For the time series, the nearest to the station grid point from the $1 \mathrm{~km}$ grid was selected for each location (RS, AS, MS, KS). Additionally, the observed time series were obtained by averaging the 5-min mean wind speeds over an hour. 
(a)

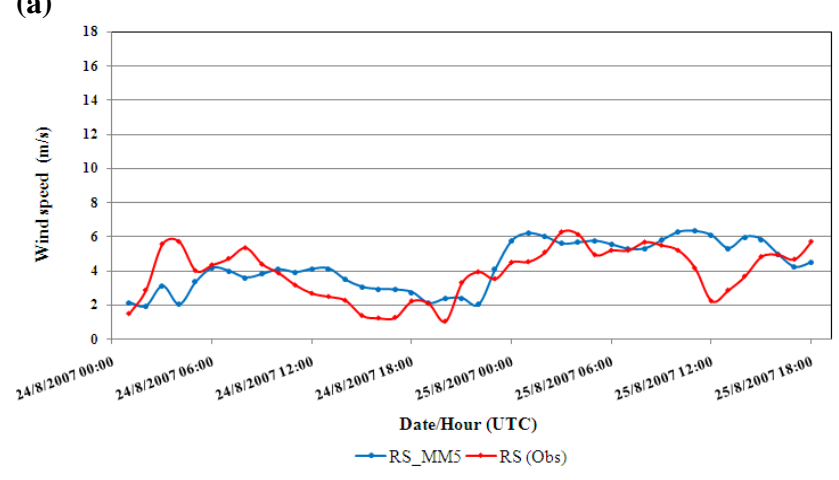

(b)

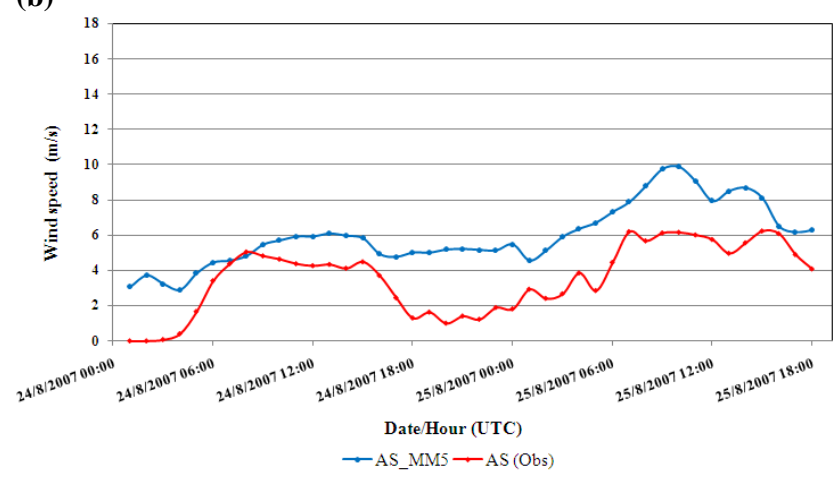

(c)

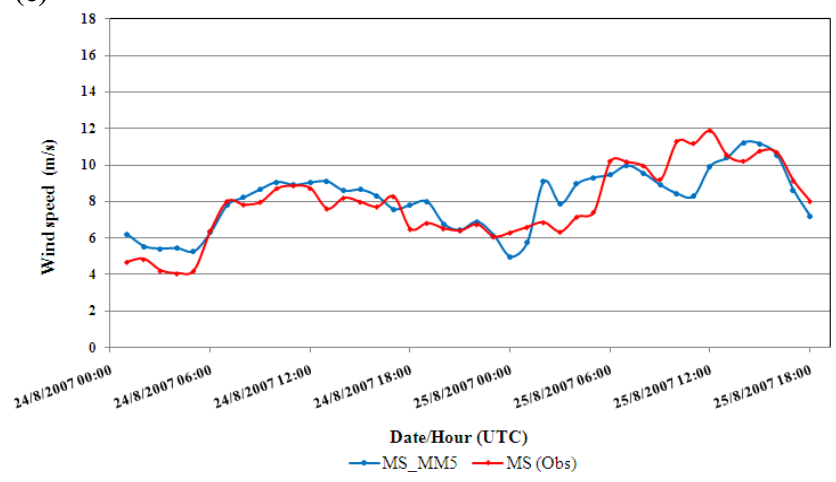

(d)

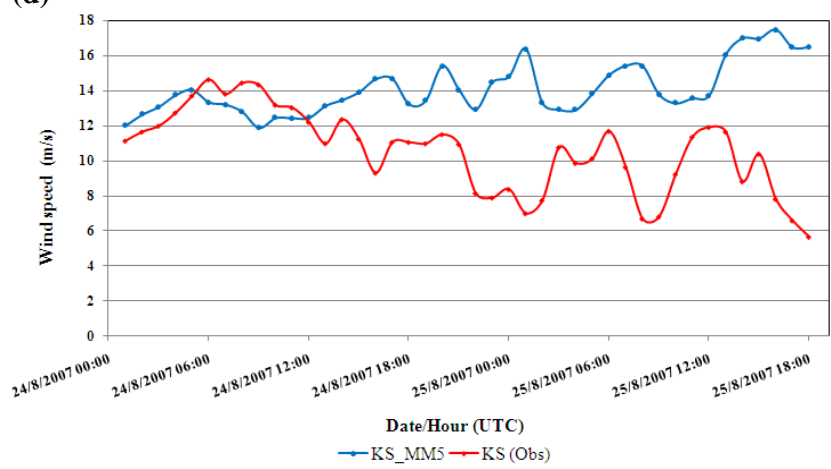

Fig. 5. Wind speed at $10 \mathrm{~m}$ as observed from the ground station (red solid line) and as simulated by MM5 Grid 3 (blue solid line) from 00:00 UTC 24 August 2007 to 18:00 UTC 25 August 2007 (42 h time period simulation) at (a) Rethymno (RS), (b) Armeni (AS), (c) Mourne (MS), (d) Kerame (KS).
The qualitative comparison between the observed and the simulated wind speeds (Fig. 5) show a good agreement except at the AS and the gap exit KS in which the model simulation overestimates the wind speed. At the gap exit (KS) unlike the observations, the simulated gap flow reached its maximum value around the noon hours of 25 August. This discrepancy could be attributed to the model pressure difference which is $1-2 \mathrm{hPa}$ greater than the observed (not shown), resulting in increasing the wind speeds.

Two parameters the Froude number $F r$, defined by $U / N h_{\mathrm{m}}$ and the Rossby number $R o$, defined by $U / f l_{\mathrm{m}}$ modulate the wind flow in the presence of complex topography (Pierrehumbert and Wyman, 1985; Smith, 1989), where $U$ is the wind speed normal to the barrier, $h_{\mathrm{m}}$ the height of the barrier, $f$ the Coriolis parameter, $l_{\mathrm{m}}$ is the half width of the barrier and $N$ is the Brunt-Vaisala frequency. In the rotating case, these two parameters are used to describe the atmospheric response to flow impinging upon mountains with the threshold values are $F r<1$ for blocking and $R o>1$ for upstream deceleration. Thus, in order to quantify the effect of the orographic influence on the wind flow the two numbers have been calculated based on MM5 model outputs at 06:00 UTC 24 August.

The calculated values of the above parameters in the area north of Crete have been evaluated by the model to a mean value $\sim 10^{-2} \mathrm{~s}^{-1}$ for Brunt-Vaisala frequency, with a mean flow of $6 \mathrm{~m} \mathrm{~s}^{-1}$, Coriolis parameter $\sim 10^{-4} \mathrm{~s}^{-1}$, a mountain height of $1300 \mathrm{~m}$ (resolved mean height of the Cretan mountains at the $1 \mathrm{~km}$ model resolution) and a mountain half width $l_{\mathrm{m}} \sim 20 \mathrm{~km}$. The above values give $F r=0.46$ and $R o=3$, implying the favorable conditions for a partial blocking of the upstream flow and a considerable deceleration upstream of the mountain barrier.

\subsection{Vertical analyses}

In order to study the vertical structure of the wind gap flow, cross-sections as well as model soundings within the study domain from $1 \mathrm{~km}$ grid resolution will be discussed in the following.

Figure 6 shows a north-south cross section, following the bold line $\mathrm{AA}^{\prime}$ in Fig. 2, along the gap which passes through its entrance (RS) and exit (KS), valid at 06:00 UTC $24 \mathrm{Au}-$ gust. The sloping as well as the mountainous character of the gap is evident. The gap flow rapidly descended near the gap exit, creating an area of strong winds $\left(\sim 16 \mathrm{~m} \mathrm{~s}^{-1}\right)$ at low levels below $\sim 940 \mathrm{hPa}$. At $900-850 \mathrm{hPa}$ an area of weak flow $\left(\sim 0 \mathrm{~m} \mathrm{~s}^{-1}\right)$ above the rapidly descending isentropes is evident. Overall, the vertical structure over the gap exit is reminiscent of hydraulic flow associated with downslope windstorms, suggesting that the relatively low topographic features through the gap may have excited a mountain wave (Durran, 1990). Moreover, the topographic sloping character of this elevated sloping gap with its gentle windward slope and the steep leeward slope enhancing the occurrence of a 


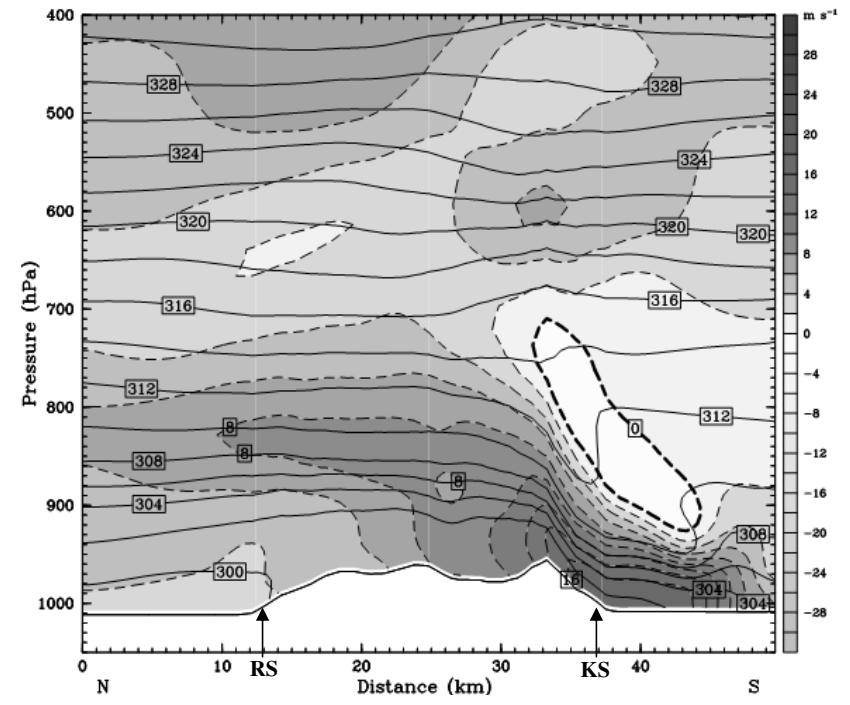

Fig. 6. North-northwestern to south-southeastern vertical cross section in the MM5 Grid 3 domain (following the bold line $\mathrm{AA}^{\prime}$ in Fig. 2) of the potential temperature (solid line at $2 \mathrm{~K}$ intervals) and of the parallel to the gap axis wind component (dashed line at $2 \mathrm{~m} \mathrm{~s}^{-1}$ ), valid at 06:00 UTC 24 August 2007 ( $6 \mathrm{~h}$ forecast). The arrows indicate the position of the gap entrance (RS) and the gap exit (KS).

mountain wave (Lilly and Klemp, 1979). Mountain waves were also evident by the rapid downward and subsequent upward shifts in the isentropes (Fudeyasu et al., 2008). Similar structures have also been noted in the lee of elevated gaps such Stampede Gap (Colle and Mass, 1998a, b) and Wide Bay, Alaska (Bond and Macklin, 1993).

The cross gap variations can be better investigated through the inspection of west-east cross sections $\mathrm{CC}^{\prime}$ and $\mathrm{BB}^{\prime}$ (bold lines in Fig. 2) which are provided in Figs. 7 and 8. The section $\mathrm{CC}^{\prime}$ (Fig. 7) cross over the location MS, while $\mathrm{BB}^{\prime}$ (Fig. 8) over the gap exit KS. At the area between the middle and near the exit of the gap (MS), the strongest gap parallel flow $\left(\sim 8 \mathrm{~m} \mathrm{~s}^{-1}\right)$ was located below $900 \mathrm{hPa}$ near the centerline of the gap (Fig. 7a). Moreover, an area of lower potential temperatures $(<302 \mathrm{~K})$ was located just over the MS location in the surface- $900 \mathrm{hPa}$ layer (Fig. 7b). This area is related with the relatively cool maritime air, which is channeled throughout the major gap. Few kilometers south, at the gap exit area (KS) the winds strengthened to $18 \mathrm{~m} \mathrm{~s}^{-1}$ (Fig. 8a) and the depth of the relatively cool maritime air layer (low potential temperature $<302 \mathrm{~K}$ ) decreased substantially (Fig. 8b).

The model-derived soundings also illustrate the vertical stratification through the gap. The model sounding at RS (Fig. 9a) reveals a $100 \mathrm{hPa}$ surface based layer, which was capped by a weak inversion layer that reached $850 \mathrm{hPa}$ with a base at $925-900 \mathrm{hPa}$. Winds near the surface were light $\left(<5 \mathrm{~m} \mathrm{~s}^{-1}\right)$, while further aloft the winds veered and weak-
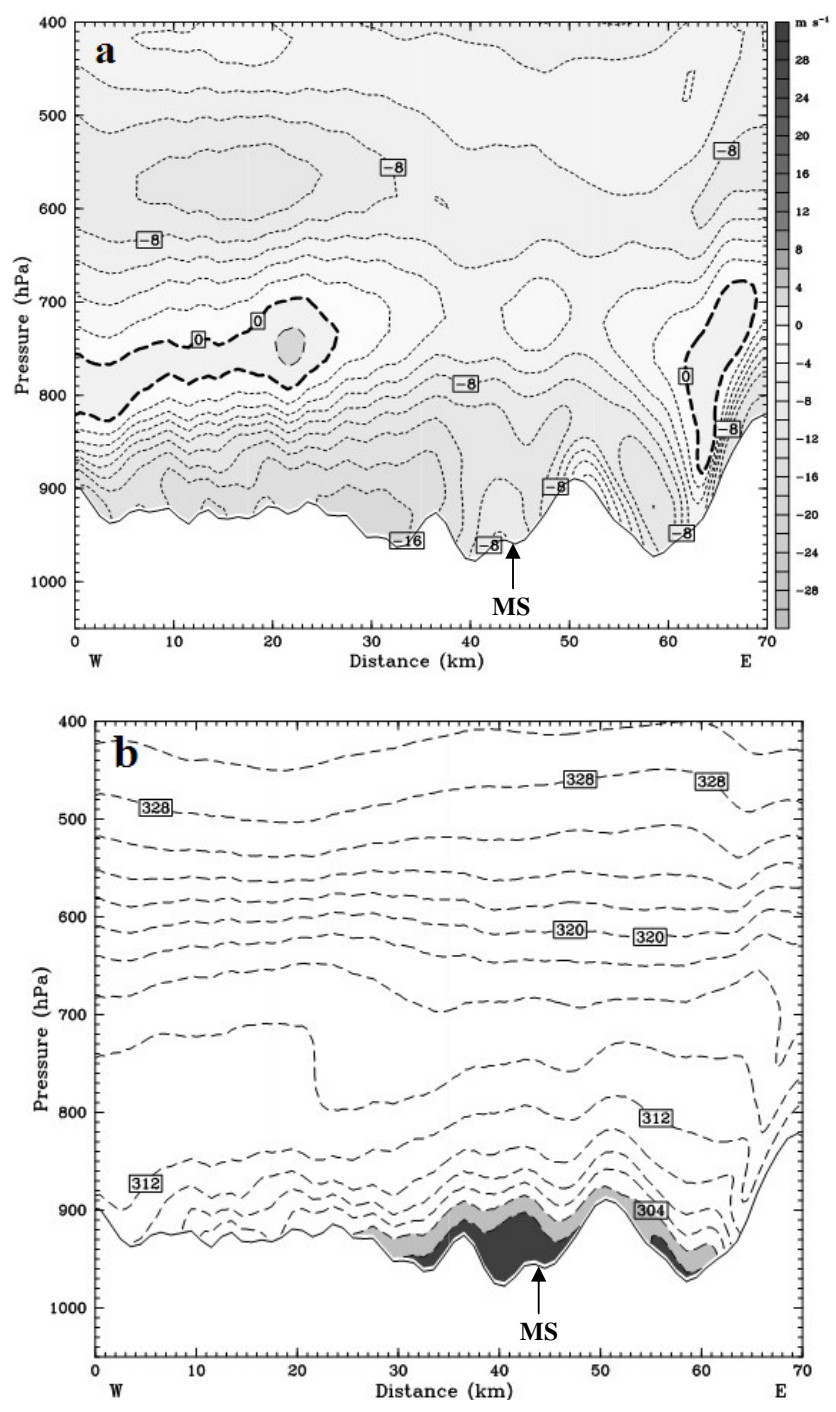

Fig. 7. West to east vertical cross section in the MM5 Grid 3 domain (following the bold line $\mathrm{CC}^{\prime}$ in Fig. 2) of the normal to cross section wind component (dashed line at $2 \mathrm{~m} \mathrm{~s}^{-1}$ ), and of (b) potential temperature (solid line at $2 \mathrm{~K}$ intervals) valid at 06:00 UTC 24 August 2007 ( $6 \mathrm{~h}$ forecast). Grey shading corresponds to potential temperature below $304 \mathrm{~K}$. The arrow indicates the position of the MS.

ened. Further downstream, at AS the vertical structure did not change significantly, while at MS (in the inner gap) a more intensified inversion layer between $900-850 \mathrm{hPa}$ was present and the low level gap flow strengthened to $7.5 \mathrm{~m} \mathrm{~s}^{-1}$ (Fig. 9b). Also, at low levels the winds turned more parallel to the gap orientation. Further analysis of the vertical stratification through the gap was performed by studying the profiles of potential temperature and wind speed (not shown) in the lower part of the atmosphere (up to $500 \mathrm{hPa}$ ). The potential temperature profile reveals a warmer as well as a drier (Fig. 9c) low level layer at KS which is probably caused by the descending air from the mountainous sloping 

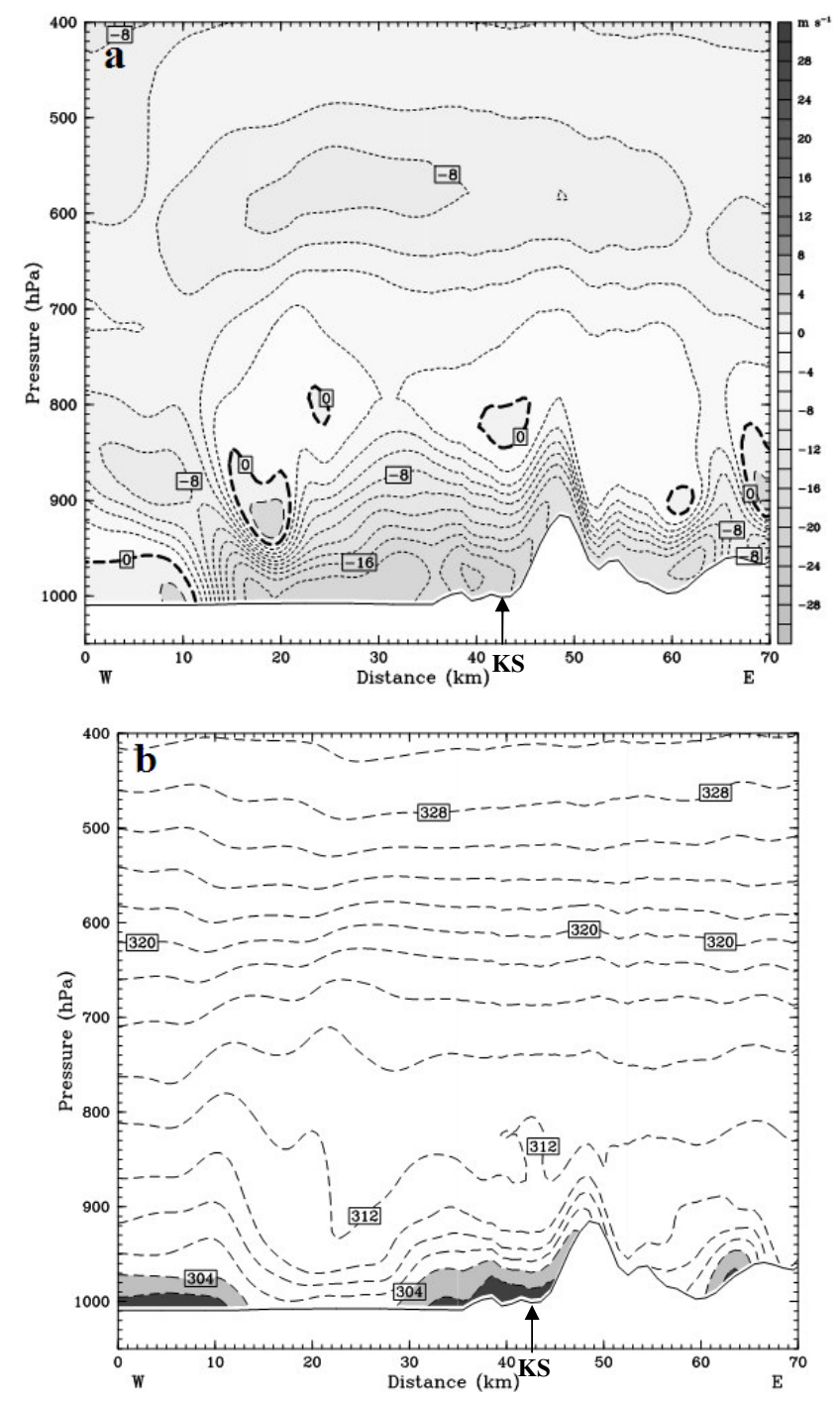

Fig. 8. West to east vertical cross section in the MM5 Grid 3 domain (following the bold line $\mathrm{BB}^{\prime}$ in Fig. 2) of the normal to cross section wind component (dashed line at $2 \mathrm{~m} \mathrm{~s}^{-1}$ ), and of (b) potential temperature (solid line at $2 \mathrm{~K}$ intervals) valid at 06:00 UTC 24 August 2007 ( $6 \mathrm{~h}$ forecast). Grey shading as in Fig. 7. The arrow indicates the position of the gap exit (KS).

gap. Moreover, the surface wind speed increased gradually from RS (northern station) down to KS (southern station) where the winds near the surface reached $\sim 18 \mathrm{~m} \mathrm{~s}^{-1}$. Contrary to the vertical profiles at RS, AS and MS in which the wind speed increased significantly with height (from surface up to $800 \mathrm{hPa}$ ), at KS (gap exit) the wind speed reduces from $18 \mathrm{~m} \mathrm{~s}^{-1}$ to $\sim 3.5 \mathrm{~m} \mathrm{~s}^{-1}$ at the level of $850 \mathrm{hPa}$. This pattern confirms the mountain wave activity at the gap exit.
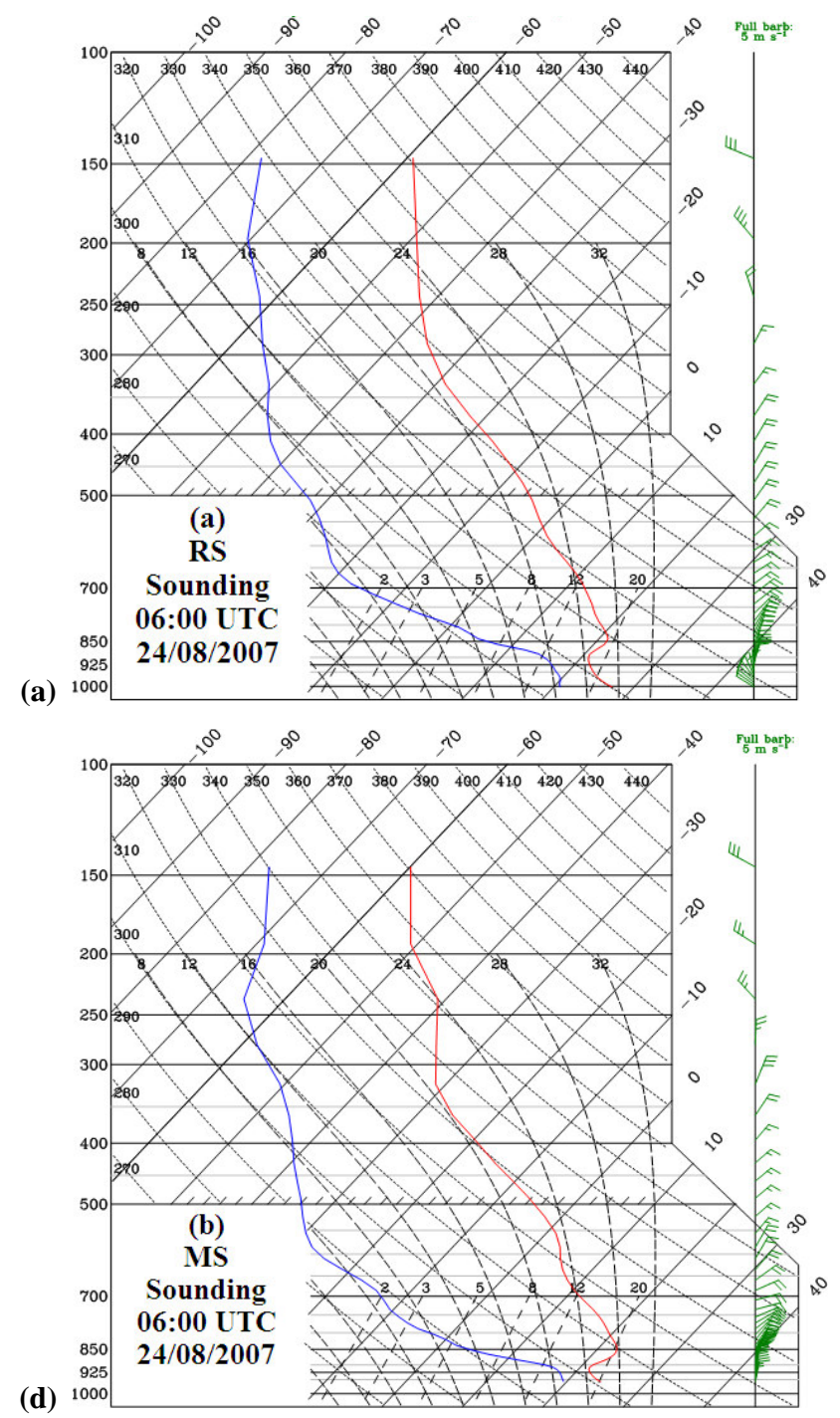

(d)

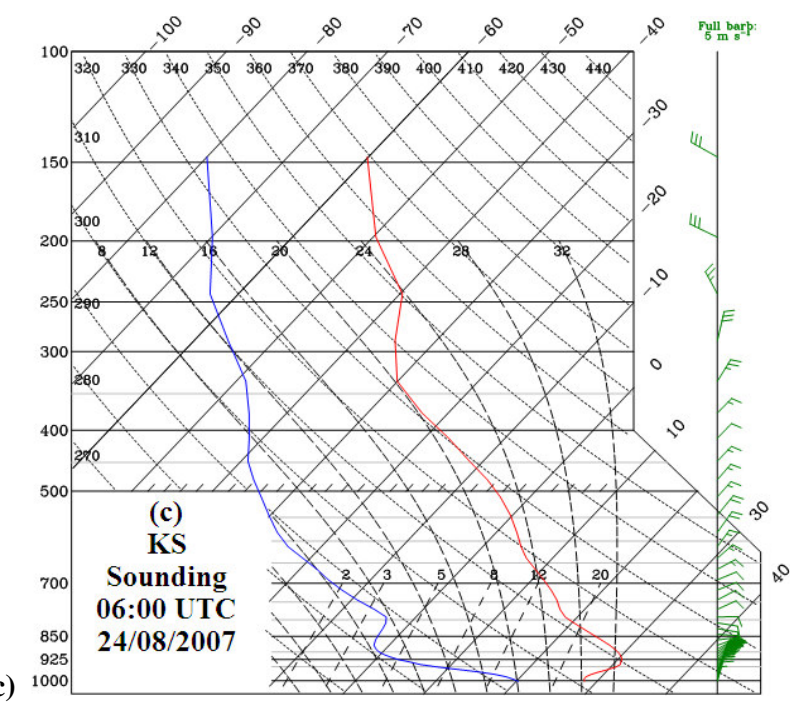

Fig. 9. Model soundings within Grid 3, at: (a) the gap entrance (RS), (b) inner the gap (MS) and (c) gap exit (KS) valid at 06:00 UTC 24 August 2007 (6 $\mathrm{h}$ forecast). 


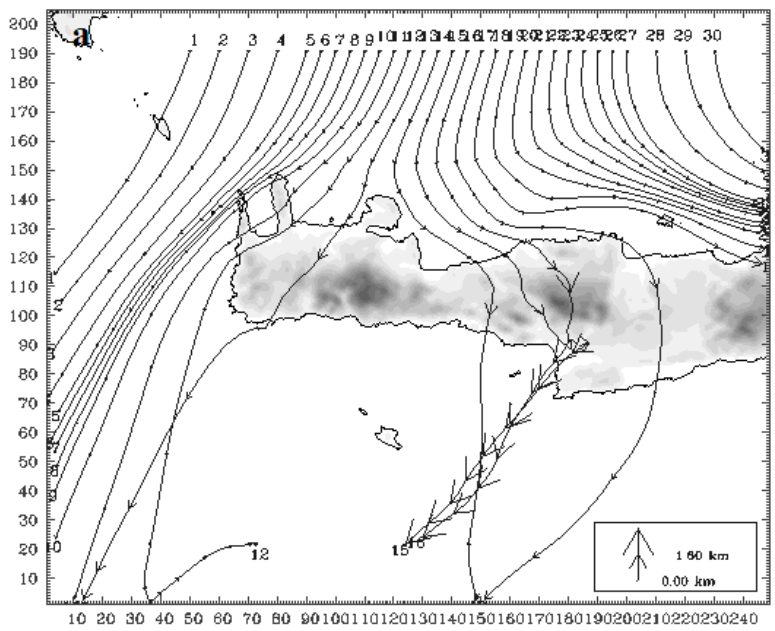

(a)

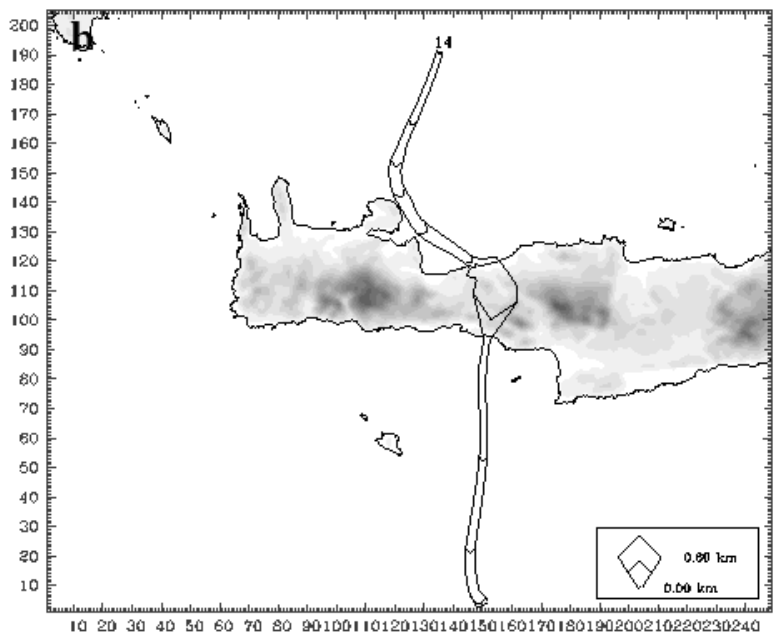

(b)

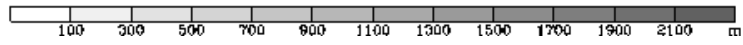

Fig. 10. (a) Forward trajectories 1-30 starting at 03:00 UTC $24 \mathrm{Au}-$ gust 2007 originating about $40 \mathrm{~m}$ above the surface (arrow representation), and (b) forward trajectory 14 concerning the major gap (ribbon representation). For both figures the arrowhead denotes the air parcel positions at $1 \mathrm{~h}$ interval. The width of each arrowhead and the width of the ribbon are proportional to the height of the trajectory at that time. Terrain shaded every $200 \mathrm{~m}$.

\subsection{Trajectories analyses}

Three dimensional 1-h forward trajectories, beginning at 03:00 UTC 24 August 2007 and terminating at 18:00 UTC 24 August 2007, elucidate the airflow over the central and western region of Crete island as well as over the major gap. An array of points north of the island was calculated using the hourly model outputs. At the height level of $\sim 40 \mathrm{~m}$ (lowest model sigma level) above the surface (Fig. 10a), trajectories 1-13 experienced a westward deflection as a result of flow deflecting around mountain Lefka Ori, while tra-
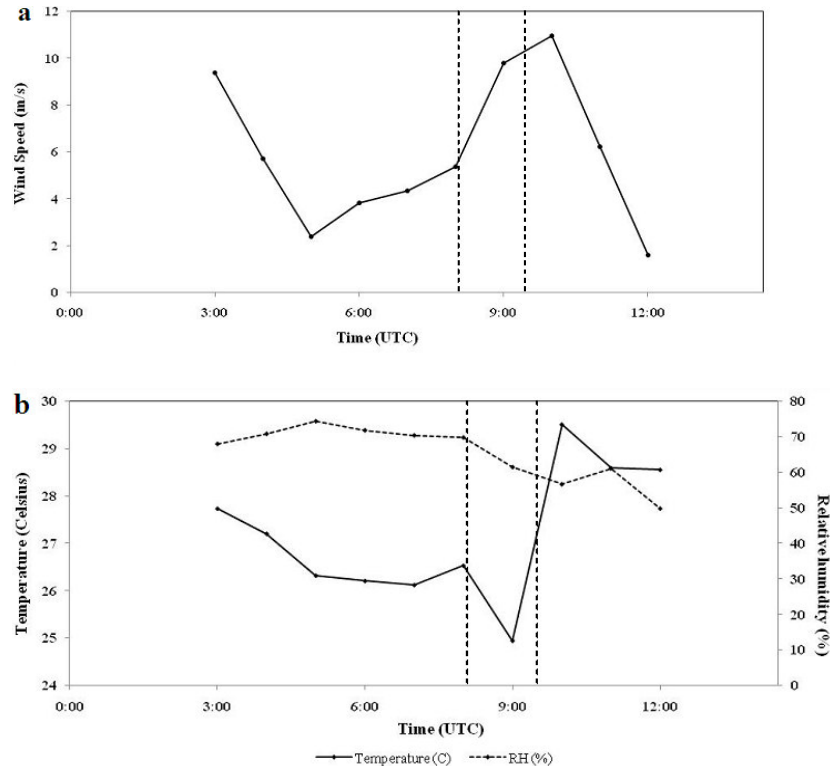

Fig. 11. (a) Wind speed (in $\mathrm{m} \mathrm{s}^{-1}$ ) and (b) temperature (in C) and relative humidity (in \%) along trajectory 14 of Fig. 10b. Dotted lines identify approximately the time the trajectory moved along the gap; the first line (from left to right) indicates the entrance and the second the exit of the trajectory.

jectory 12 far downstream of the island turned cyclonically. The turning of this trajectory as well as the wind intensity $\left(<3 \mathrm{~m} \mathrm{~s}^{-1}\right)$ is associated with the wake which is observed at the region downstream of Lefka Ori and has been reproduced adequately by QuikSCAT (Fig. 8 in K09). Trajectories 14 and 15 get channeled through the major gap as well as trajectories 16 and 17 through other secondary elevated gaps. Finally, a leftward deflection upstream of mountain Idi was simulated for a large number of trajectories (18-30).

The middle trajectories $12-16$ rise up over the terrain before descending rapidly to the surface in the southern coasts of the island as Fig. 10a depicts. Temperature and humidity field analyses for these trajectories (not shown) reveals an abrupt increase of temperature and decrease in relative humidity implying that föhn conditions (Gaffin, 2002) have been dominated during northerly wind regime at these regions. The higher values of temperature field around central and western Crete are localized over these regions as the simulated temperature field reveals (Fig. 4b).

Trajectories 14 and 15 were accelerated and descended rapidly from the hills and mountains of the elevated gap as they moved through the gap. More specifically, inside the gap the trajectory 14 experienced a rapid descent from $590 \mathrm{~m}$ to the surface near the gap exit KS (Fig. 10b). The speed of this trajectory was $5 \mathrm{~m} \mathrm{~s}^{-1}$ at the gap entrance but increased to approximately $10 \mathrm{~m} \mathrm{~s}^{-1}$ near the gap exit (Fig. 11a). A slightly flow acceleration continued over the maritime area downstream of the gap until the speed of trajectory 14 reached a maximum of $11 \mathrm{~m} \mathrm{~s}^{-1}$ just offshore of 


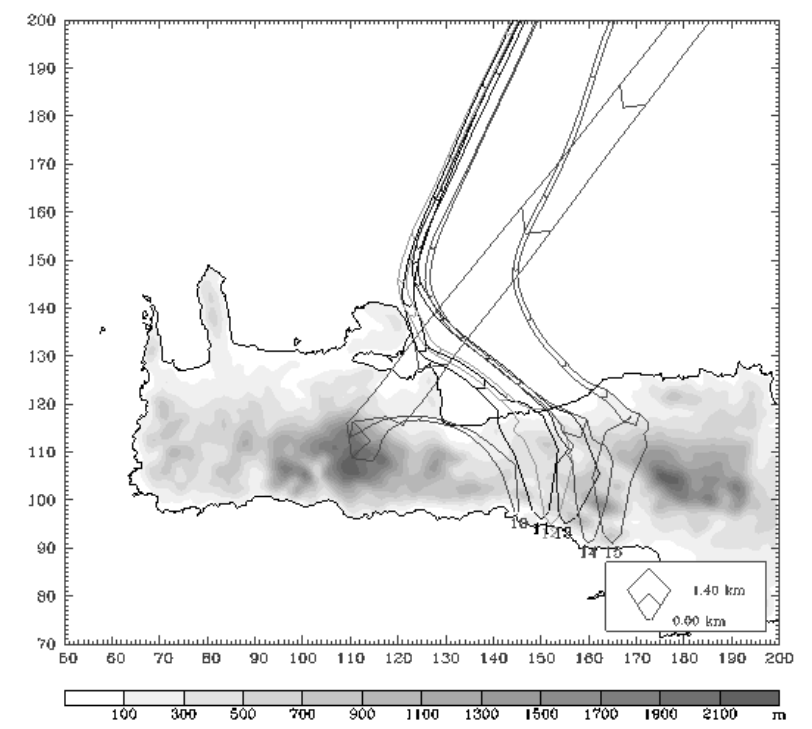

Fig. 12. Backward trajectories 10-15 starting at 06:00 UTC $24 \mathrm{Au}-$ gust 2007 originating at the lowest sigma level. The width of the ribbon is proportional to the height of the trajectory at that time and the terrain shading as in Fig. 10.

the gap exit. In the gap the trajectory subsided rapidly from $590 \mathrm{~m}$ to the surface near KS resulting in an abrupt temperature increase accompanied with a decrease in relative humidity (Fig. 11b). Also, the gradual deceleration of the wind speed with the associated leftward deflection just upstream of Lefka Ori are evident in Fig. 11b. Evidence for these trajectories exists in the surface observations, in which near moderate winds $\left(\sim 5 \mathrm{~m} \mathrm{~s}^{-1}\right)$ from northwestern direction at the gap entrance as well as stronger winds from northern direction at the gap exit were observed.

Trajectories launched approximately $500 \mathrm{~m}$ above the surface (not shown) experience less horizontal deflection as they cross the central and western part of the island rising up the lower topographic elements $(<900 \mathrm{~m})$. However, flow splitting around the highest mountains and some channeling across the major gap is evident. In the gap the channeled trajectories still experience a substantial descent to the coastal gap exit resulting in a temperature increase and relative humidity decrease.

For the 1-km domain, backward trajectories starting approximately $40 \mathrm{~m}$ above the surface at 06:00 UTC 24 August 2007 were calculated for an array of points along the gap exit region (Fig. 12). The main objective of these trajectories is to describe the origin of the strong winds along the gap exit. Trajectories ending at the gap exit, within the area of the maximum wind speeds, arrive from two basic locations. The majority of the trajectories were channeled through the sloping gap before exiting from it. In contrast, trajectory 10 , is moved in higher altitudes compared to the other trajectories upstream of the island and when impinged on Lefka Ori it deflected and descended rapidly from $1300 \mathrm{~m}$ to the surface in the gap exit region.

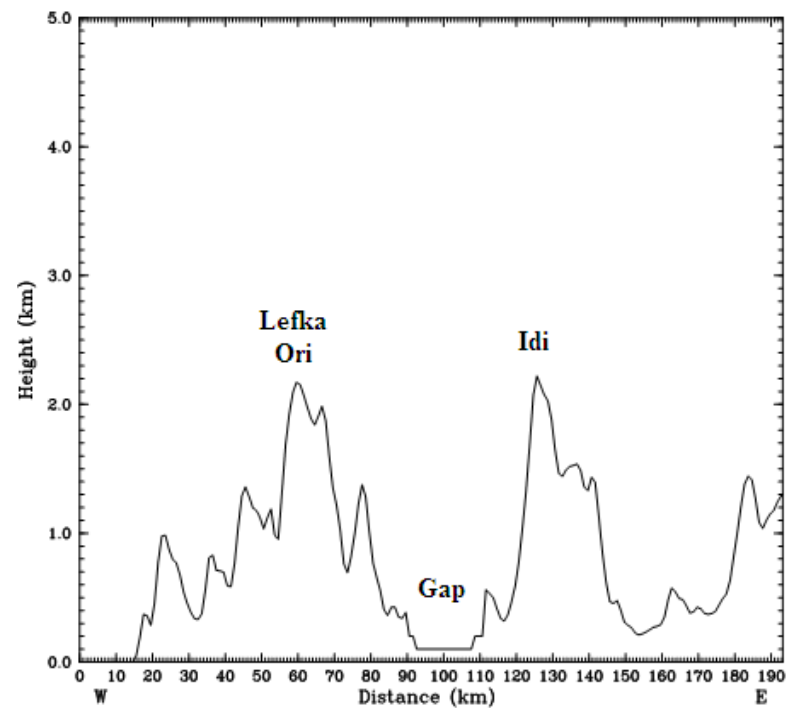

Fig. 13. The modified island profile used in FULLGAP simulation. The mountains as well as the gap location are marked.

\section{Model results - sensitivity tests}

From the above trajectories analysis, it appears that air parcels have some tendency to pass through the major gap between the highest Cretan mountains. So, an important question is what role does the complex topography of the gap play in such strong winds at the gap exit. In order to investigate this issue, a sensitivity experiment has been conducted, that was identical to the $1-\mathrm{km}$ resolution experiment already discussed, except that for this simulation the terrain inside the gap, between the mountains Lefka Ori and Idi (Fig. 1a), was decreased at a lower constant height level $(\sim 100 \mathrm{~m})$ (FULLGAP, hereafter). The vertical profile of the new terrain is illustrated in Fig. 13.

Figure 14a shows the wind field at $10 \mathrm{~m}$ from the FULLGAP experiment during the time of the maximum winds, while Fig. 14b shows the difference in the $10 \mathrm{~m}$ winds between the FULLGAP and CNTL simulations at 06:00 UTC 24 August 2007. Even though the gap terrain was changed completely, the general airflow around the island did not modify substantially. However, the winds immediately downwind of the gap exit were about $2-4 \mathrm{~m} \mathrm{~s}^{-1}$ weaker than the CNTL run. Also, notably differences are found at the maritime area downwind of the gap because of the gap outflow expansion of about $10 \mathrm{~km}$ eastern in comparison with the CNTL run due to the absence of the higher topography near the eastern part of gap exit.

To further illustrate the changes produced by modifying the terrain of the gap, Fig. 15 shows cross section taken across the modified gap (same location as in CNTL run) at 06:00 UTC 24 August 2007 for the FULLGAP simulation. For this simulation (Fig. 15) the subsidence and the winds over the gap exit were much weaker than in the CNTL run. 

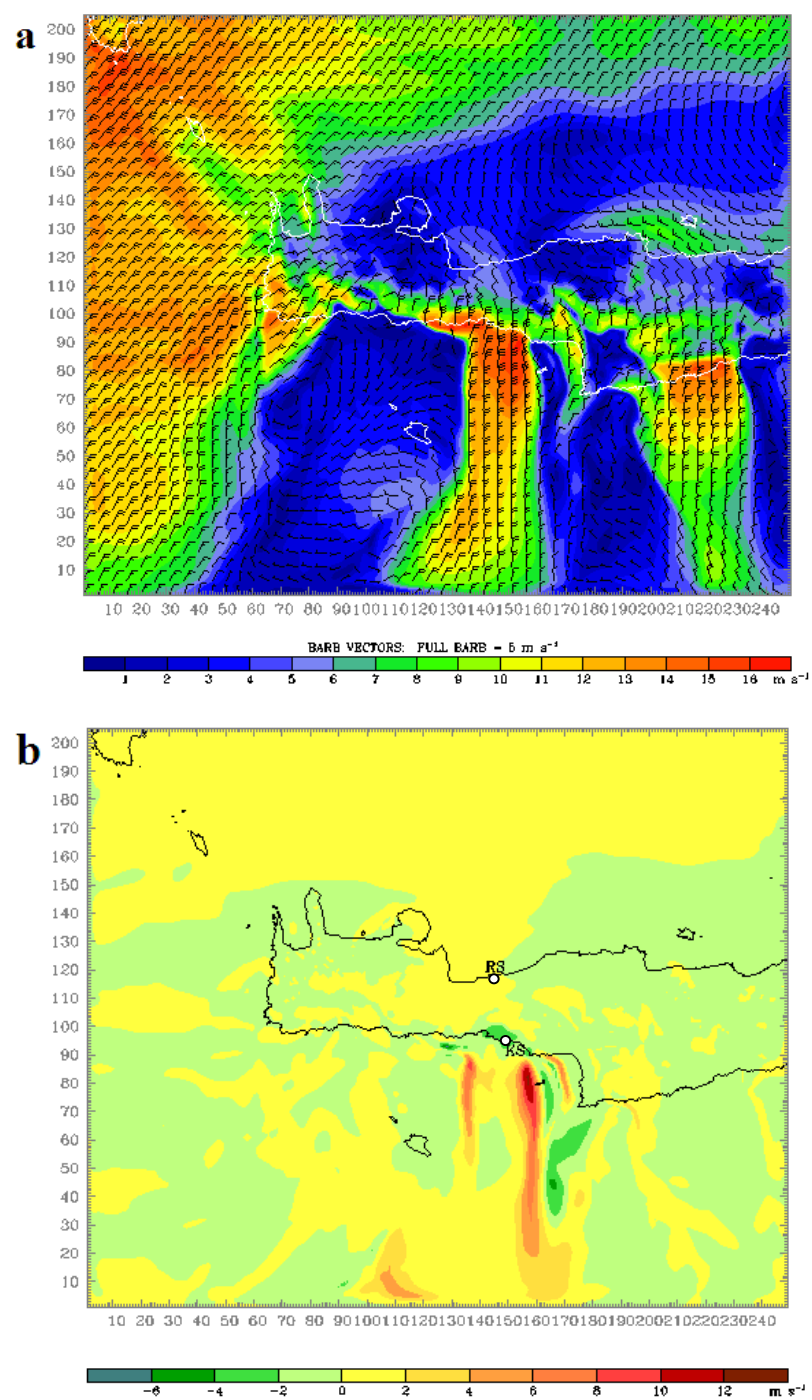

Fig. 14. Plan view of $10 \mathrm{~m}$ wind from Grid 3, valid at 06:00 UTC 24 August 2007 (6h forecast) from the (a) FULLGAP simulation, (b) $10 \mathrm{~m}$ wind speed differences (FULLGAP minus CNTL) at 06:00 UTC 24 August 2007. Also, the locations of the gap entrance and exit stations (RS and KS, respectively) are indicated.

However, it should be noted that the stronger winds are still located at the gap exit. This pattern is similar to the one found in a sea level gap exit without topographic elements such as Juan de Fuca, between western Washington State and British Columbia (Colle and Mass, 2000 - cross section AA' in their study).

In conclusion, this case study has aspects of both gap outflow (removing the inside gap terrain) and characteristics of downslope flow (mountain wave activity). The importance of the leeside mountain wave in controlling the strength of the flow at the gap exit is similar to that found for elevated gaps such as Stampede Gap in central Washington Cascades (Colle and Mass, 1998a) and in the lee of Chivela Pass in Mexico (Steenburgh et al., 1998).

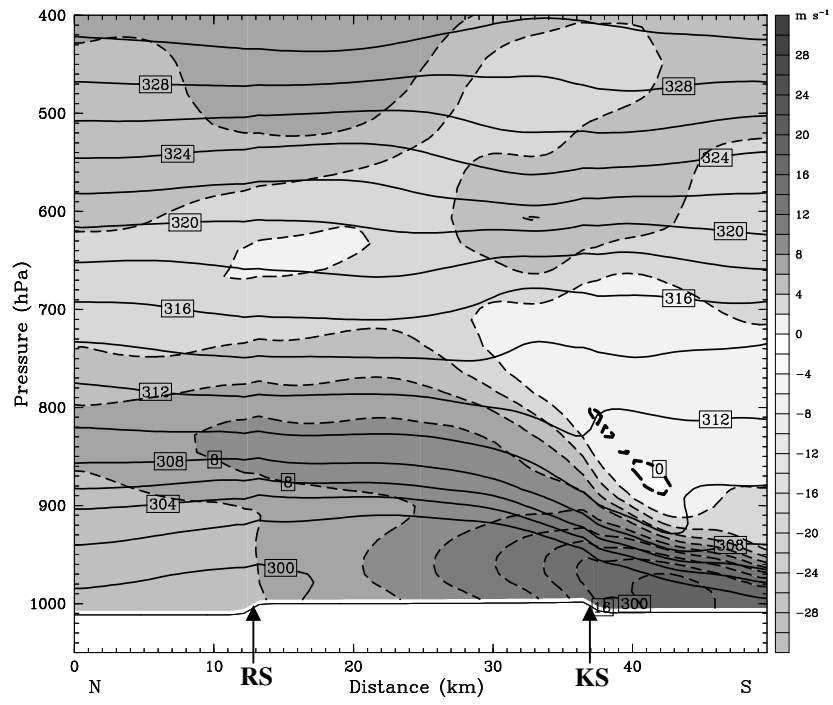

Fig. 15. North-northwestern to south-southeastern vertical cross section (as in Fig. 6), valid at 06:00 UTC 24 August 2007 (6h forecast) for FULLGAP simulation. The arrows indicate the position of the gap entrance (RS) and the gap exit (KS).

\section{Conclusions}

In the frame of this study the significance of gap flow through the major gap between the two high Cretan mountains Lefka Ori and Idi has been examined. During the summer months when a northerly wind regime is established over the Aegean, strong northerly winds are observed at the abovementioned gap exit. Since the maritime gap exit is an important waterway for commercial and recreational use and the associated strong winds inside the gap many times cause the rapid spread of forest fires at adjacent mountainous areas, the study of the three dimensional structure and the physical mechanism of this gap flow is essential.

For this purpose the most intense episode of northern winds over the Aegean throughout summer 2007 have been simulated. During the days of 24-25 August 2007, when an Etesian wind regime was established, near gale winds occurred at the southern coasts of Crete Island and especially through the major gap in which wind gusts at the gap exit (KS) exceeded $24 \mathrm{~m} \mathrm{~s}^{-1}$ (K09). The study was based on the analysis of model simulations performed with the nonhydrostatic model MM5 with a horizontal grid increment of $1 \mathrm{~km}$. The synoptic pattern of these days was captured adequately by the model revealing a strong pressure gradient over the Aegean Sea $(5 \mathrm{hPa} / 300 \mathrm{~km})$, with a surface low $\sim 1006 \mathrm{hPa}$ over the southern Turkey and Cyprus and high pressures prevailing over the Balkans and the Greek territory.

Many of the observed structures relating with the general flow around the island were realistically simulated; such as the upstream deceleration up to $90 \mathrm{~km}$ north from the coast 
and the noticeable gradual leftward turn of the wind. The model estimated Froude number $(F r=0.46)$ and Rossby number $(R o=3)$ support this atmospheric response to flow impinging upon mountains. Moreover, downstream of the island the formation of two mountain wakes behind the two highest Cretan mountains as well as the restricted areas with strong winds were revealed by the model simulations. These areas were associated with the gap outflow; where just offshore of the major gap the wind speed exceeded $10 \mathrm{~m} \mathrm{~s}^{-1}$. The model also maintained the swath of the northerly winds far downstream $(40-50 \mathrm{~km})$ where a gradual deceleration of the wind speed occurred, which is in accordance with the associated observed downstream flow (Fig. 8 in K09's study).

The simulated stronger winds within the gap area are found near the gap exit. This study supports the aspects of works of Overland and Walter (1981) and Colle and Mass (2000), who showed that gap flow cannot be described in terms of "funnel" dynamics (Venturi effect) associated with mass conservation (Reed, 1931). With funnel mechanisms one would except the maximum winds where the gap is narrowest; however, model results as well as in situ observations (K09) reveal that the maximum winds were at the gap exit. The comparison between the observed and the simulated time series of wind speed inside the gap reveals that the model was in qualitative agreement with the observations; however, the model overestimated the pressure field by $1-$ $2 \mathrm{hPa}$ which resulted in $2-5 \mathrm{~m} \mathrm{~s}^{-1}$ stronger winds than the observed at the gap exit (KS).

The vertical analyses present structures similar to downslope windstorms, suggesting that the gap topography can excite a mountain wave. As a result of this suggestion the gap flow descended abruptly at the gap exit creating the observed strong winds. Moreover, the simulated vertical cross sections reveal that the maritime air was channeled throughout the gap and the downslope flow off the peaks of the gap contributed to the shallower gap flow over the gap exit. In addition, the model sounding at KS reveals a drier and warmer low stable layer in relation to the inside gap stations (AS, MS) which is accompanied with strong winds. This low level layer at KS probably is related to the descending air from the elevated gap. In order to investigate further this aspect trajectory analysis has been done.

A large number of trajectories from the 1-km simulation experienced a deflection upstream of the two highest mountains as well as a channeling through the elevated gaps. Trajectories analyses reveal that air parcels rise up over the terrain before descending rapidly in the southern coasts of the island resulting in an increase of surface temperature and a decrease in relative humidity. The blocking of maritime air at low levels capped by an inversion force the upper air to descend from the summit level to the surrounding lowland and undergo an adiabatic compression (Barry, 2008). This type of föhn, without moisture removal on the windward slope, was first noted by Hann (1885) and has subsequently been widely demonstrated. Inside the major gap, the channeled air parcels experienced acceleration from $5 \mathrm{~m} \mathrm{~s}^{-1}$ to $\sim 10 \mathrm{~m} \mathrm{~s}^{-1}$. The rapidly descending of trajectory from $\sim 600 \mathrm{~m}$ to surface at $\mathrm{KS}$ also shows föhn characteristics.

Furthermore, the results from the sensitivity tests showed that elevation changes within the gap affect the evolution and the dynamics of the gap winds and the associated gap outflow. This aspect is in accordance with many studies in which the varying elevations inside an elevated gap play an important role in the gap winds (Colle and Mass, 1998a, b; Bond and Stabeno, 1998). Moreover, the major conclusion resulting from both control and sensitivity simulations supports the aspect that gap and downslope winds may occur simultaneously (CNTL) producing stronger winds than observed in lower gaps (FULLGAP) (Sharp and Mass, 2004).

Since this gap event is observed almost every summer, contrary to other strong gap flows around the world which in their majority are created by the approach of a synoptic scale disturbance (e.g. in Stampede Gap, Colle and Mass, 1998a, b), the results of this study have shown the considerable potential of mesoscale models to realistically simulate the structures and the evolution associated with these strong winds in elevated gaps with complex topography. However, there is a need to also investigate more thoroughly the role of the channeling inside the narrow straits between the numerous islands of the Aegean and to understand better the organization of the flow over the Aegean Sea. The need for high quality and detailed weather information at local scale for human activities, including navigation, is an important issue in modern society. This task can be fulfilled by the use of more powerful models and remote sensing techniques, and it is the authors' intention to continue this research to meet these objectives.

Acknowledgements. ECMWF is kindly acknowledged for the provision of gridded analyses data. The authors are grateful to Spyridon Lykoudis (National Observatory of Athens, Greece) for his valuable comments on the paper. Special thanks to the Municipality of Rethymno for its help and collaboration.

Edited by: G. Boni

Reviewed by: R. Romero and two other anonymous referees

\section{References}

Akylas, E., Kotroni, V., and Lagouvardos, K.: Sensitivity of high resolution operational forecasts to the choice of the planetary boundary layer scheme, Atmos. Res., 84, 49-57, 2007.

Barry, G. R.: Mountain Weather and Climate, Boulder, 3rd edn., Cambridge University Press, 2008.

Bond, N. A. and Stabeno, P. J.: Analysis of surface winds in Shelikof Strait, Alaska, using moored buoy observations, Weather Forecast., 13, 547-559, 1998.

Bond, N. A. and Macklin, S. A.: Aircraft observations of off-shoredirected flow near Wide Bay, Alaska, Mon. Weather Rev., 121, 150-161, 1993. 
Cadez, M.: Über synoptische Probleme in Südostalpinen Raum, Veröff. Schweiz, Met. Zentralanstalt, 4, 155-75, 1967.

Colle, B. A. and Mass, C. F.: Windstorms along the western side of the Washington Cascade Mountains. Part I: A high-resolution observational and modeling study of the 12 February 1995 Event, Mon. Weather Rev., 126, 28-52, 1998a.

Colle, B. A. and Mass, C. F.: Windstorms along the western side of the Washington Cascade Mountains. Part II: Characteristics of past events and three-dimensional idealized simulations, Mon. Weather Rev., 126, 53-71, 1998b.

Colle, B. A. and Mass, C. F.: High-resolution observations and numerical simulations of easterly gap flow through the Strait of Juan de Fuca on 9-10 December 1995, Mon. Weather Rev., 128, 2398-2422, 2000.

Doyle, J. D.: The influence of mesoscale orography on a coastal jet and rainband. prediction, Mon. Weather Rev., 125, 1465-1488, 1997.

Dudhia, J.: A non-hydrostatic version of the Penn State/NCAR mesoscale model: validation tests and simulation of an Atlantic cyclone and cold front, Mon. Weather Rev., 121, 1493-1513, 1993.

Durran, D. R.: Mountain waves and downslope winds, in: Atmospheric Processes Over Complex Terrain, edited by: Blumen, W., Am. Meteorol. Soc., Boston, MA, Meteorological Monograph, 23(45), 59-81, 1990.

Fudeyasu, H., Kuwagata, T., Ohasi, Y., Suzuki, S., Kiyohara, Y., and Hozumi, Y.: Numerical study of the local downslope wind "Hirodo-Kaze" in Japan, Mon. Weather Rev., 136, 27-40, 2008.

Gaffin, D. M.: Unexpected warming induced by foehn winds in the lee of the Smoky mountains, Weather Forecast., 17, 907-915, 2002.

Gohm, A., Mayr, G. J., Fix, A., and Giez, A.: On the onset of bora and the formation of rotors and jumps near a mountain gap, Q. J. Roy. Meteor. Soc., 134, 21-46, 2008.

Hann, J.: Einige Bermerkungen zur Entwicklungs-Geschichte der Ansichten über den Ursprung des Föhns, Meteorol. Z., 2, 393-9, 1885.

Hong, S.-Y. and Pan, H.-L.: Nonlocal boundary layer vertical diffusion in a medium-range forecast model, Mon. Weather Rev., 124, 2322-2339, 1996.

Hsu, S. A.: Coastal Meteorology, Academic Press, 261 pp., 1988.

Kain, J. S. and Fritsch, J. M.: Convective parameterization for mesoscale models: The Kain-Fritsch scheme. The Representation of Cumulus in numerical models, Am. Meteorol. Soc., Meteor. Mon., 46, 165-177, 1993.

Koletsis, I., Lagouvardos, K., Kotroni, V., and Bartzokas, A.: The interaction of northern wind flow with the complex topography of Crete Island - Part 1: Observational study, Nat. Hazards Earth Syst. Sci., 9, 1845-1855, doi:10.5194/nhess-9-1845-2009, 2009.

Kotroni, V. and Lagouvardos, K.: Evaluation of MM5 highresolution real-time forecasts over the urban area of Athens, Greece, J. Appl. Meteorol., 43, 1666-1678, 2004.
Kotroni, V. and Lagouvardos, K.: Precipitation forecast skill of different convective parameterization and microphysical schemes: application for the cold season over Greece, Geophys. Res. Let., V 108(10), 1977-1980, 2001.

Kotroni, V., Lagouvardos, K., and Lalas, D.: The effect of the island of Crete on the Etesian winds over the Aegean Sea, Q. J. Roy. Meteor. Soc., 127, 1917-1937, 2001.

Legeckis, R.: Upwelling off the Gulfs of Panama and Papagayo in the tropical Pacific during March 1985, J. Geophys. Res., 93, 15485-15489, 1988.

Lilly, D. K. and Klemp, J. B.: The effect of terrain shape on nonlinear hydrostatic mountain waves, J. Fluid Mech., 95, 241-61, 1979.

Mayr, G. J., Armi, L., Gohm, A., Zängl, G., Durran, D. R., Flamant, C., Gaberšek, S., Mobbs, S., Ross, A., and Weissmann, M.: Gap flows: Results from the Mesoscale Alpine Programme, Q. J. Roy. Meteor. Soc., 133, 881-896, 2007.

Mass, C. F., Businger, S., Albright, M. D., and Tucker, Z. A.: A windstorm in the lee of a gap in a coastal mountain barrier, Mon. Weather Rev., 123, 315-331, 1995.

Metaxas, D. A.: Air-sea interaction in the Greek seas and resulted Etesian wind characteristics, Ioannina Univ., School of Physics \& Mathematics, Technical Report No 5, 32 pp., 1973.

Metaxas, D. A. and Bartzokas, A.: Pressure covariability over the Atlantic, Europe and N. Africa. Application: centers of action for temperature, winter precipitation and summer winds in Athens, Greece, Theor. Appl. Climatol., 49, 9-18, 1994.

Meteorological Office: Weather in Mediterranean, Vol. I, General Meteorology, 2nd edn., H.M.S.O., London, 1962.

Overland, J. E. and Walter Jr., B. A.: Gap winds in the Strait of San Juan de Fuca, Mon. Weather Rev., 109, 2221-33, 1981.

Pierrehumbert, R. T. and Wyman, B.: Upstream effects of mesoscale mountain ridges, J. Atmos. Sci., 42, 977-1003, 1985.

Reed, T. R.: Gap winds in the Strait of Juan de Fuca, Mon. Weather Rev., 59, 373-376, 1931.

Schultz, P.: An explicit cloud physics parameterization for operational numerical weather prediction, Mon. Weather Rev., 123, 3331-3343, 1995.

Sharp, J. and Mass, C. F.: Columbia Gorge Gap Winds: Their Climatological Influence and Synoptic Evolution, Weather Forecast., 19, 970-992, 2004.

Smith, R. B.: Synoptic observations and theory of orographically disturbed wind and pressure, J. Atmos. Sci., 39, 60-70, 1982.

Smith, R. B.: Mountain-induced stagnation points in hydrostatic flow, Tellus A, 41, 270-4, 1989.

Smith, R. B., Gleason, A. C., Gluhosky, P. A., and Grubisic, V.: The wake of St. Vincent, J. Atmos. Sci., 54, 606-623, 1997.

Steenburgh, W. J., Schultz, D. M., and Colle, B. A.: The structure and evolution of gap outflow over the Gulf of Tehuantepec, Mexico, Mon. Weather Rev., 126(10), 2673-91, 1998.

Ziv, B., Saaroni, H., and Alpert, P.: The factors governing the summer regime of the eastern Mediterranean, Int. J. Climatol., 24, 1859-1871, 2004. 